\title{
Testing of cerebrospinal compensatory reserve in shunted and non-shunted patients: a guide to interpretation based on an observational study
}

\author{
Marek Czosnyka, Helen Whitehouse, Piotr Smielewski, Sreten Simac, John D Pickard
}

\begin{abstract}
Objective-To design a computerised infusion test to compensate for the disadvantages of Katzman's lumbar infusion method: inadequate accuracy of estimation of the resistance to cerebrospinal fluid outflow and poor predictive value in normal pressure hydrocephalus.

Methods-Accuracy was improved by intracranial pressure signal processing and model analysis for measurement of cerebrospinal compensatory variables. These include the CSF outflow resistance, brain compliance, pressure-volume index, estimated sagittal sinus pressure, CSF formation rate, and other variables. Infusion may be made into the lumbar space, ventricles, or, when assessing shunt function in vivo, the shunt chamber.
\end{abstract}

Results and conclusions-The computerised test has been used for five years in a multicentre study in $\mathbf{3 5 0}$ hydrocephalic patients of various ages, aetiologies, and states of cerebrospinal compensation. The principles of using the test to characterise different types of CSF circulatory disorders in patients presenting with ventricular dilatation, including brain atrophy and normal and high pressure hydrocephalus, are presented and illustrated. Previous studies showed a positive correlation between cerebrospinal compensatory variables and the results of shunting, but such a prediction remains difficult in idiopathic normal pressure hydrocephalus, particularly in elderly patients. The technique is helpful in the assessment of shunt malfunction, including posture-related overdrainage, overdrainage related to the nocturnal $B$ wave activity, and proximal or distal shunt obstruction.

The appendix presents an introduction to the mathematical modelling of CSF pressure volume-compensation included in computerised infusion test software.

(F Neurol Neurosurg Psychiatry 1996;60:549-558)

Keywords: hydrocephalus; cerebrospinal fluid; infusion test; modelling; hydrocephalus shunts

Hydrocephalus is more complex than a simple disorder of the CSF circulation. ${ }^{1-5}$ As shunting is a purely mechanistic treatment, the biomechanics of a patient's pressure-volume compensation should be ideally examined before a shunt is implanted. Such an examination, although invasive, may help with the decision as to whether to shunt, and with possible complications such as shunt blockage and under and overdrainage.

The role of a shunt is to correct the disturbances of CSF circulation or outflow by a reduction of the resistance to CSF outflow to about $5-10 \mathrm{~mm} \mathrm{Hg} / \mathrm{ml} / \mathrm{min}$ - the typical hydrodynamic resistance of most shunts. If a patient has normal intracranial pressure and a normal resistance to CSF outflow $(6-10 \mathrm{~mm}$ $\mathrm{Hg} / \mathrm{ml} / \min ^{6}{ }^{7}$ ), a shunt theoretically cannot help because the resistance cannot be reduced further without the risk of overdrainage. The fundamental role of the volume-pressure study is to measure the resistance to CSF outflow along with other compensatory variables and consider whether the disturbed cerebrospinal compensation can be improved by shunting. Therefore, the examination may help to avoid unnecessary shunting or shunt revision. ${ }^{8-11}$

Almost all authors ${ }^{711-17}$ agree that in hydrocephalus the drainage of CSF is disturbed, which may be expressed quantitatively by a raised resistance to CSF outflow. The limit of normal resistance is around 12 or $13 \mathrm{~mm}$ $\mathrm{Hg} / \mathrm{ml} / \mathrm{min} .^{7911121416}$ However, raising of this resistance is not always correlated with a good outcome after shunting ${ }^{18-20}$-particularly in idiopathic normal pressure hydrocephalus in elderly patients. ${ }^{13}$ Our experience suggests that not only the resistance but also other compensatory variables are helpful in the diagnosis of hydrocephalus. ${ }^{11}$ 21-24

As the rate of shunt failure is around $20 \%-30 \%$ during the first year after implantation and continues at a rate of $5 \%$ per year, ${ }^{25}$ the probability of shunt malfunction over time is high. A blocked shunt does not always produce the dramatic onset of clinical symptoms, ${ }^{26}{ }^{27}$ that justifies a shunt revision without performing an invasive examination. Not uncommonly the CSF circulatory reserve deteriorates gradually and a question about the shunt function may be very difficult to answer. In such cases, pressure-volume studies may help to assess the severity of malfunction by comparing the current test to the study performed before shunting. ${ }^{26}{ }^{28}$ Therefore an important role of a preshunting test is to establish the baseline for comparison with postshunting investigations performed to test the shunt's function in vivo.

The main aim of this observational study is to present the methods of computer supported analysis of CSF pressure used for diagnosis of hydrocephalus, and show how the results of 


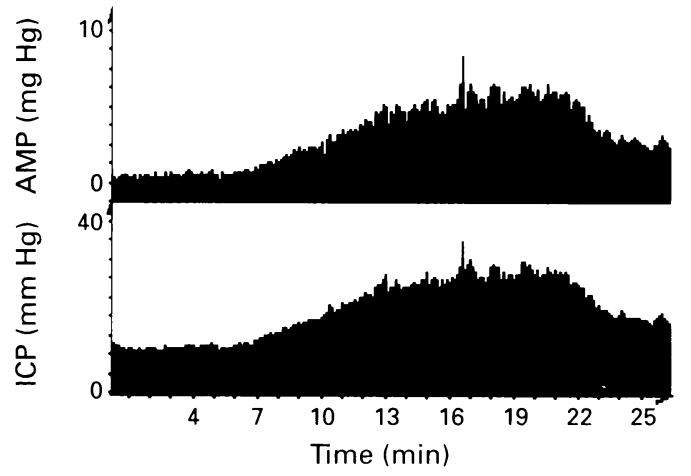

Figure 1 Mean pulse amplitude of CSF pressure (AMP) and mean pressure (ICP) recorded during infusion test ( $x$ axis: time in minutes from the beginning of recording). The infusion of $1.5 \mathrm{ml} / \mathrm{min}$ starts in the fifth minute and finishes around the 22nd minute.

computerised infusion tests are able to distinguish different types of disorders presenting with ventricular dilatation. The computerised infusion test is faster, less invasive, and does not demand specialised equipment as required by other methods described. ${ }^{29}{ }^{31}$ The principles of interpretation of the pressure-volume tests performed to assess shunt function in vivo are also discussed.

\section{Materials and methods}

Three hundred and fifty infusion tests were performed in three different centres (136 in children) at the Child's Health Centre in Warsaw (Poland), Medical Academy Hospital in Warsaw (Poland), and at Addenbrooke's Hospital in Cambridge (UK). All patients presented with ventricular dilatation and had hydrocephalus diagnosed by other clinical examinations. In 59 patients the test was performed to assess shunt function in vivo.

There were almost no serious complications after the test (one case of epidural abscess).

COMPUTERISED INFUSION TEST

The computerised infusion test ${ }^{32}$ is a method for the accurate analysis of the traditional constant rate infusion. ${ }^{1028}{ }^{33}$ This method allows an infusion to be made into any accessible fluid compartments. Lumbar infusion, even if it has understandable limitations, is less invasive and, therefore, more often performed. The second most frequent approach is an intraventricular infusion into a subcutaneously positioned reservoir, connected to an intraventircular catheter. In such cases two hypodermic needles (gauge 23 or less, as advised by manufacturer of a specific type of reservoir) are used: one for the pressure measurement and the second for the infusion.

\section{THEORETICAL FRAMEWORK}

The model of cerebrospinal volume compensation investigated during this test was described by Marmarou and coworkers ${ }^{34}{ }^{35}$ and slightly modified later. ${ }^{36.38}$ Apart from resting CSF pressure and the resistance to CSF outflow, the pressure-volume index (PVI), cerebrospinal compliance, CSF formation rate, and the pulse wave amplitude of CSF pressure

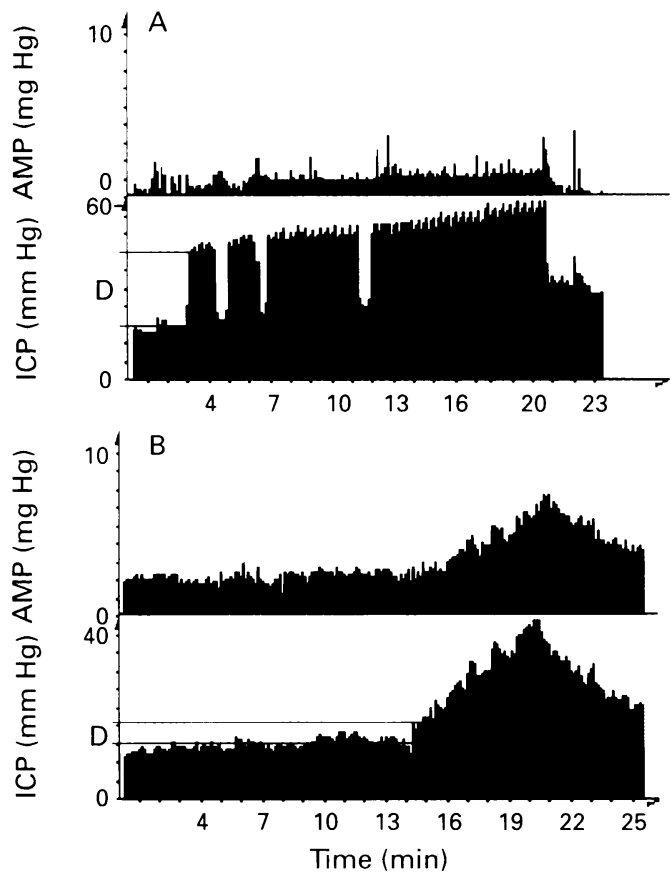

Figure 2 (A) Example of the lumbar infusion test made through one lumbar needle (G19). The end of the needle was partially obstructed, therefore the pressure gradient $D$ $=25 \mathrm{~mm} \mathrm{Hg}$ across the needle was recorded during the infusion (rate $1.5 \mathrm{ml} / \mathrm{min}$ ). Infusion was discontinued around the fifth, seventh, and 12th minute to control the real level of CSF pressure. (B) Example of an infusion into the Ommaya reservoir. Rapid pressure increase $D$ was around $1.5 \mathrm{~mm} \mathrm{Hg}$ indicating that the ventricular catheter was patent.

are measured (see appendix for definitions). During the infusion, the computer calculates mean pressure and pulse amplitude and presents both variables with time along the $\mathrm{x}$ axis (fig 1). The resistance to CSF outflow is calculated as the difference between the value of the plateau pressure during infusion and the resting pressure, divided by the infusion rate. However, in many cases strong vasogenic waves or an excessive increase of the pressure above the safe limit of $40 \mathrm{~mm} \mathrm{Hg}$ do not allow the precise measurement of the final pressure plateau. Computerised analysis, on the other hand, produces results even in difficult cases when the infusion is terminated prematurely. The algorithm utilises a complex time series analysis for volume-pressure curve retrieval, ${ }^{3 \times}$ the least mean square model fitting, ${ }^{32}$ and an examination of the relation between the pulse amplitude and the mean CSF pressure (for details see the appendix)..$^{243739}$

\section{ONE NEEDLE TEST}

A lumbar infusion performed using two separate needles inserted one or two intervertebral spaces apart is the most precise way of pressure-volume testing in communicating hydrocephalus. Exceptionally, in difficult cases the lumbar infusion may be performed using the same needle for the infusion and pressure measurement, although the gauge should not be higher than 21 . Normally, the resistance of the needle is low (around $1-2 \mathrm{~mm} \mathrm{Hg} / \mathrm{ml} / \mathrm{min}$ ), but this may increase considerably after the insertion into the lumbar CSF space if the end 
Figure 3 Example of simultaneous recording of CSF pressure (ICP) and $M C A$ blood flow velocity (FV) using a TCD ultrasonograph. Strong $B$ waves seen in ICP are obviously in phase with fluctuations of blood flow during periods $A$ and $C$. During period $B$, the frequency of fluctuations of blood flow increased, causing a decrease in the amplitude of $B$ waves in ICP. During period $D$, the $B$ waves disappeared.

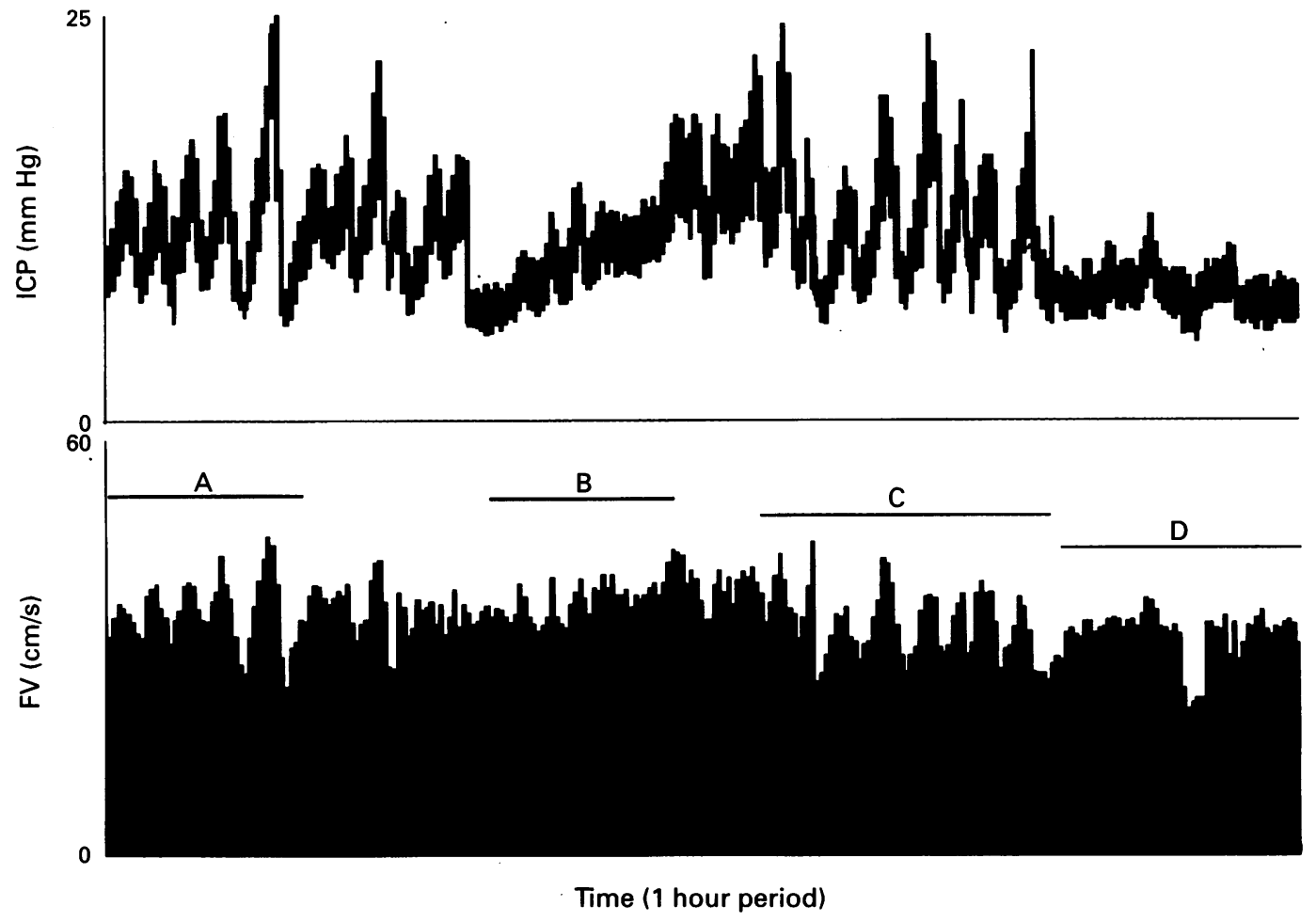

of the needle is touching neural roots or any other tissue. An infusion rate of 1.0 or $1.5 \mathrm{ml} / \mathrm{min}$ may produce a sudden increase in the measured pressure with a subsequently slow rise (fig 2A). The initial rapid pressure increase represents the pressure gradient across the needle. The slow increase ( $>5 \mathrm{~min}$ ) represents the real rise of the pressure inside the CSF compartment which may be measured using short breaks during infusion ( $<30 \mathrm{~s}$ ). For analysis, the pressure recorded during the infusion should be decreased by the pressure gradient across the needle.

INFUSION INTO A SUBCUTANEOUS RESERVOIR OR SHUNT CHAMBER

In a pressure-volume study performed using two needles inserted into a reservoir or shunt chamber the analysis may be complicated by an additional pressure gradient across the ventricular catheter. The resistance of a patent intraventricular catheter is lower than $1 \mathrm{~mm}$ $\mathrm{Hg} / \mathrm{ml} / \mathrm{min}$. An infusion rate of $1.0-1.5 \mathrm{ml} / \mathrm{min}$ produces almost negligible initial rapid increase of the pressure (less than $1.0-1.5 \mathrm{~mm}$ $\mathrm{Hg}$; fig 2B). If the initial rise is higher, the data should be analysed as in the one needle infusion study - that is, the initial rapid increase in the pressure should be subtracted from the slow asymptotic increase. Again, two or three short intermediate breaks in infusion (every five minutes) are recommended to control the real increase in the pressure within the ventricles. If the fast initial increase in the pressure is higher than $3 \mathrm{~mm} \mathrm{Hg}$, it suggests a partial obstruction of the ventricular catheter.

LONG TERM MONITORING OF CSF PRESSURE The presence of " $B$ waves" in the recorded CSF pressure ${ }^{4041}$ is reported to be a good prognostic factor in shunting. ${ }^{184243}$ There is still no agreement about the nature of these waves, which have a character of periodic oscillations of duration from 20 seconds to one or two minutes. This kind of oscillation can be recorded in cerebral blood flow velocity in normal volunteers and seems to be correlated with an REM phase of sleep. ${ }^{44}$ Similar waves can be seen in arterial blood pressure and heart rate in patients with severe head injury with low cerebral perfusion pressure. ${ }^{45}$ Whatever the source of these waves, they are associated with oscillations of the cerebral blood volume. When the cerebrospinal compensatory reserve is low they produce synchronised oscillations in CSF pressure. In the classic flow chart for the investigation of hydrocephalus in adults, presented by Gjerris et $a l,{ }^{42}$ shunting is advised when the $\mathrm{B}$ waves are present for more than $50 \%$ of monitoring time or the baseline pressure is raised above $15 \mathrm{~mm} \mathrm{Hg}$. However, it is not clear at which amplitude $B$ waves should be interpreted as pathological: waves of amplitude from $1 \mathrm{~mm} \mathrm{Hg}$ to $25 \mathrm{~mm} \mathrm{Hg}$ can be seen in the same patient (fig 3) and detected using computer data processing. ${ }^{47-49}$

\section{Results and interpretations}

DIFFERENTIATION BETWEEN BRAIN ATROPHY

AND NORMAL PRESSURE HYDROCEPHALUS

Patients with predominantly brain atrophy (48 patients were diagnosed) had a normal CSF circulation, by contrast with hydrocephalic patients. Typically, the opening pressure, the resistance to CSF outflow, and the pulse amplitude were low (ICP $<12 \mathrm{~mm} \mathrm{Hg}$, RCSF $<12 \mathrm{~mm} \mathrm{Hg} / \mathrm{ml} / \mathrm{min}$, amplitude $<2 \mathrm{~mm} \mathrm{Hg}$ ). The pressure volume index was high (PVI $>20$ $\mathrm{ml}$ ), reflecting low elasticity of the atrophic brain. There were no vasogenic waves seen in the pressure recording (fig $4 \mathrm{~A}$ ). In this situa- 
Figure 4 Typical infusion tests performed in patients presented with: $(A)$ brain atrophy; (B) normal pressure hydrocephalus; (C) non-communicating hydrocephalus (lumbar infusion); (D) acute communicating hydrocephalus (after subarachnoid haemorrhage).
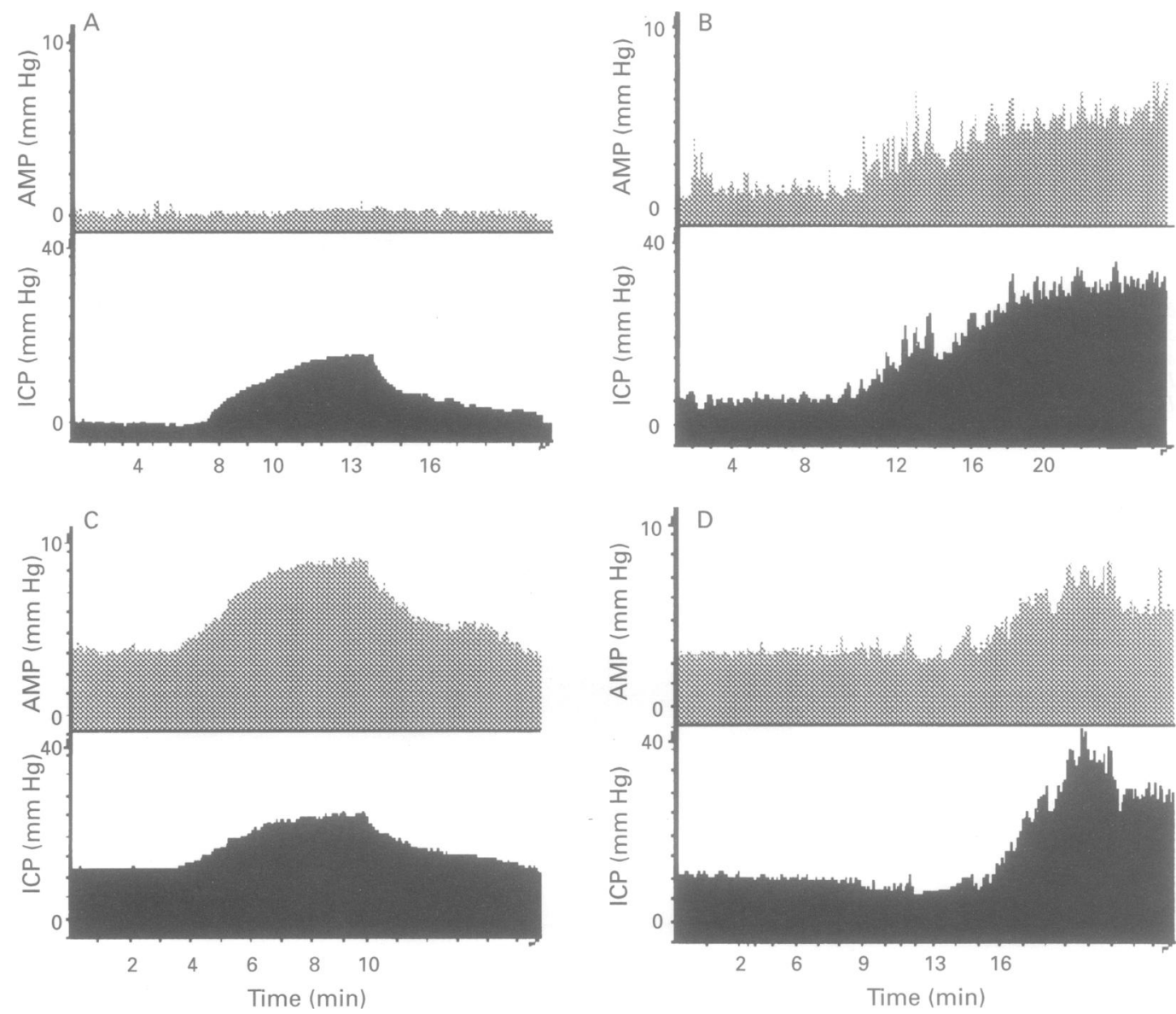

tion the CSF spaces are being inflated and deflated passively, like a balloon.

Normal pressure hydrocephalus (101 patients) was characterised by a normal opening pressure (ICP $<15 \mathrm{~mm} \mathrm{Hg}$ ) and high PVI $(>20 \mathrm{ml})$. Again, as in brain atrophy, the CSF system was very compliant. ${ }^{1114}$ The increased resistance to CSF outflow (>12 mm $\mathrm{Hg} / \mathrm{ml} / \mathrm{min}$ ) and $\mathrm{B}$ waves seen during infusion, particularly prominent when ICP increases, allow normal pressure hydrocephalus to be distinguished from atrophy (fig 4B).

NON-COMMUNICATING HYDROCEPHALUS

Lumbar infusion is not recommended in noncommunicating hydrocephalus both because of the subsequent risk of herniation and because of the misleading results obtained. However, this type of hydrocephalus may not always be detected by initial CT. In those few patients in whom lumbar infusion was performed (12), the resistance to CSF outflow was normal, because the lumbar infusion was not able to detect the proximal narrowing in CSF circulatory pathways. The resting pressure, pulse amplitude, and paradoxically, PVI were all high (ICP > $12 \mathrm{~mm} \mathrm{Hg}$, pulse amplitude $>4 \mathrm{~mm} \mathrm{Hg}$, PVI $>18 \mathrm{ml}$; fig $4 \mathrm{C}$ ).

The same type of hydrocephalus investigated using ventricular infusion (via a reservoir, seven patients), showed high resting pressure and high resistance to CSF outflow high (ICP >15 mm Hg, RCSF >13 mm $\mathrm{Hg} / \mathrm{ml} / \mathrm{min})$. The PVI was low $(<13 \mathrm{ml})$ and the pulse amplitude was high $(>4 \mathrm{~mm} \mathrm{Hg})$ indicating a poor compensatory reserve. Acute communicating hydrocephalus (after subarachnoid haemorrhage), when problems with CSF circulation arise from insufficient reabsorption or circulation of CSF over the brain convexity (39 patients) gave the same pattern of variables, regardless of whether the lumbar or ventricular approach was used (fig 4D).

\section{IS CLASSIFICATION ALWAYS POSSIBLE ?}

In 84 patients unqualified differentiation between atrophy, normal pressure hydrocephalus, and non-communicating and acute hydrocephalus was not possible. Some 56 patients fell into the border range between ther overnight ICP monitoring with continuous assessment of the magnitude and frequency of $\mathbf{B}$ waves helped in making the decision about shunting. In 24 patients overnight ICP dynamics were limited with very little vasomotor pressure activity.

CHANGE IN THE PROFILE OF CEREBROSPINAL COMPENSATION AFTER SHUNTING

The computerised infusion test was used to assess shunt function in vivo in 59 shunted patients. With a shunt functioning properly (26 patients), the resistance to CSF outflow never exceeds $10 \mathrm{~mm} \mathrm{Hg} / \mathrm{ml} / \mathrm{min}$, an exception being the flow regulating Orbis-Sigma valve. ${ }^{50}$ The resting pressure remained at or below the shunt's opening pressure. Tests repeated after shunting should always be considered in comparison with the test performed before surgery. Abnormal cerebrospinal compensatory variables such as high resting preshydrocephalus and atrophy. In 32 patients fur- 

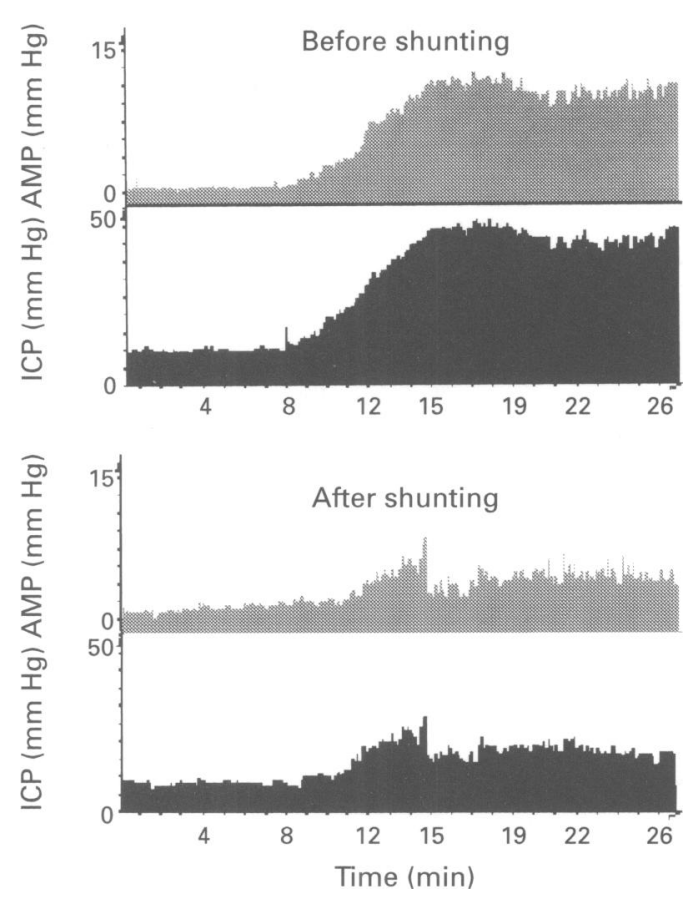

Figure 5 Infusion test made in a patient (after subarachnoid haemorrhage) before and after shunting (Pudenz medium pressure valve). The change in opening pressure was minimal ( $8 \mathrm{~mm} \mathrm{Hg}$ before, $7 \mathrm{~mm} \mathrm{Hg}$ after), but resistance to CSF outflow decreased from $20 \mathrm{~mm}$ $\mathrm{Hg} / \mathrm{ml} / \mathrm{min}$ to $6 \mathrm{~mm} \mathrm{Hg/ml/min}$. PVI did not change.

sure, increased resistance to CSF outflow, or decreased PVI should return to normal after successful shunting. In valves having a low hydrodynamic resistance and well defined opening pressure a sharp plateau of the pressure trend is seen about $1-5 \mathrm{~mm} \mathrm{Hg}$ above the level of shunt's opening pressure (fig 5)..$^{138}$

\section{DETERMINATION OF SHUNT PATENCY}

There are three main methods to assess CSF dynamics in shunted patients. Firstly, the simplest and the least invasive way is a measurement of intraventricular pressure using a previously implanted subcutaneous CSF reservoir. Lumbar puncture in communicating hydrocephalus (27 patients) or the measurement of the pressure inside the chamber of the shunt (12 patients) -when the shunt's construction allows such a procedure-were also possible.

Pressure measurement and infusion into the shunt chamber is only possible with shunts having a CSF sampling reservoir proximal to the valve. Therefore the method is not useful for the testing of all burr hole valves.

With the pressure measurement inside the shunt chamber, the presence of a CSF pressure pulse wave and a pressure increase in response to coughing should confirm pressure transmission between the needle and the CSF space, proving patency of the ventricular catheter. However, the CSF flow through the shunt may itself attenuate these pressure fluctuations. In cases of absent pulse waveform or a weak response to coughing it is useful to block the shunt distally by depression of an occluder, or distal section of outlet catheter to confirm that during proximal obstruction waves do not appear.
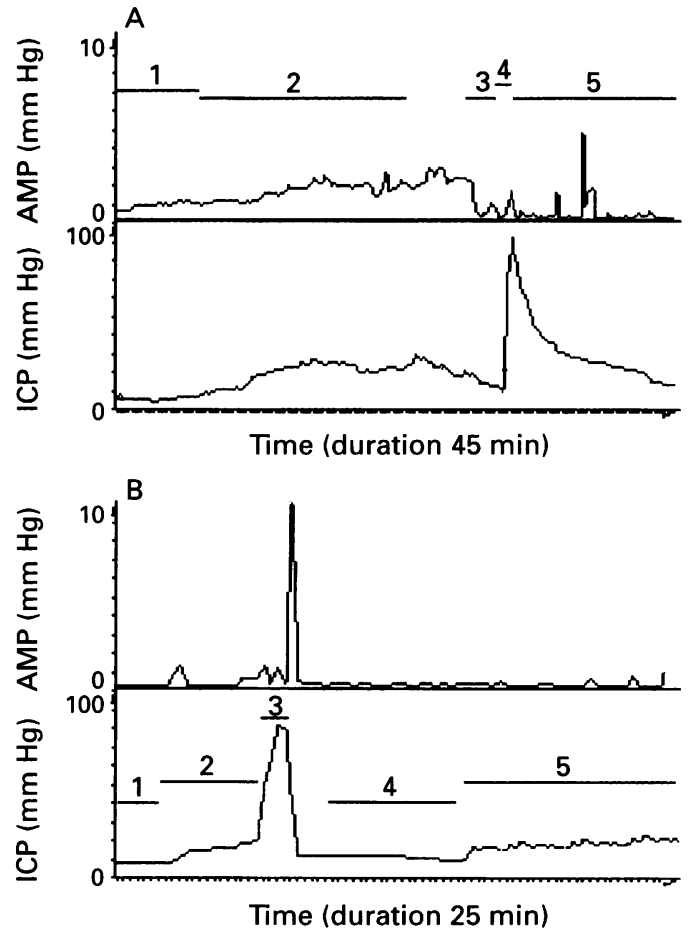

Figure 6 Two examples of tests performed to check for the shunt patency using both recording from and infusion into the shunt's chamber. (A) Peritoneal catheter or valve blocked: 1 -baseline recording with good pulse amplitude $(A M P) ; 2$-infusion with distal occluder depressed (resistance to CSF outflow $=14 \mathrm{~mm} \mathrm{Hg} / \mathrm{ml} / \mathrm{min}$ ); 3 after the proximal occluder was pressed the pulse amplitude disappeared; 4 infusion with proximal occluder closed: the pressure increased immediately to $90 \mathrm{~mm} \mathrm{Hg}$; 5 -slow decrease in pressure with proximal occluder closed, showing that the shunt was not blocked totally but rather partially obstructed. (B) Ventricular catheter blocked: 1-baseline recording with the pulse amplitude absent; 2-distal occluder closed; 3 -infusion with the distal occluder closed: the pressure increased quickly to $80 \mathrm{~mm} \mathrm{Hg}$ and resolved immediately after the release of the distal occluder; 4 baseline monitoring with proximal occluder closed followed by the infusion 5-showing patent valve and distal catheter (resistance $4 \mathrm{~mm} \mathrm{Hg/ml/min).}$

When the shunt or chamber have proximal and distal occluders or may be occluded by percutaneous pressure on the inlet or outlet tubes an infusion into shunt chamber is performed first with the distal occluder closed. The resistance to CSF outflow and PVI should not be dramatically different from the values measured before shunting. If RCSF is higher (> 20\%) and PVI much lower (<50\%) than before shunting, a partial obstruction of the proximal drain, or obstruction of the CSF space (as in slit ventricle syndrome), are likely (five patients). The infusion is repeated with the proximal occluder closed. Pressure should not rise higher than $4-5 \mathrm{~mm} \mathrm{Hg}$ above the shunt's opening pressure (again, the flow regulating Orbis-Sigma valve is an exception ${ }^{50}$ ). If it does, an obstruction of the distal catheter or valve blockage is likely (four patients; fig 6).

\section{OVERDRAINAGE RELATED TO POSTURE}

This may be assessed using a tilting armchair (four patients). When the baseline pressure measured in the horizontal body position is low (usually negative), overdrainage is possible. A change of posture to sitting, with the transducer kept at the same level relative to 

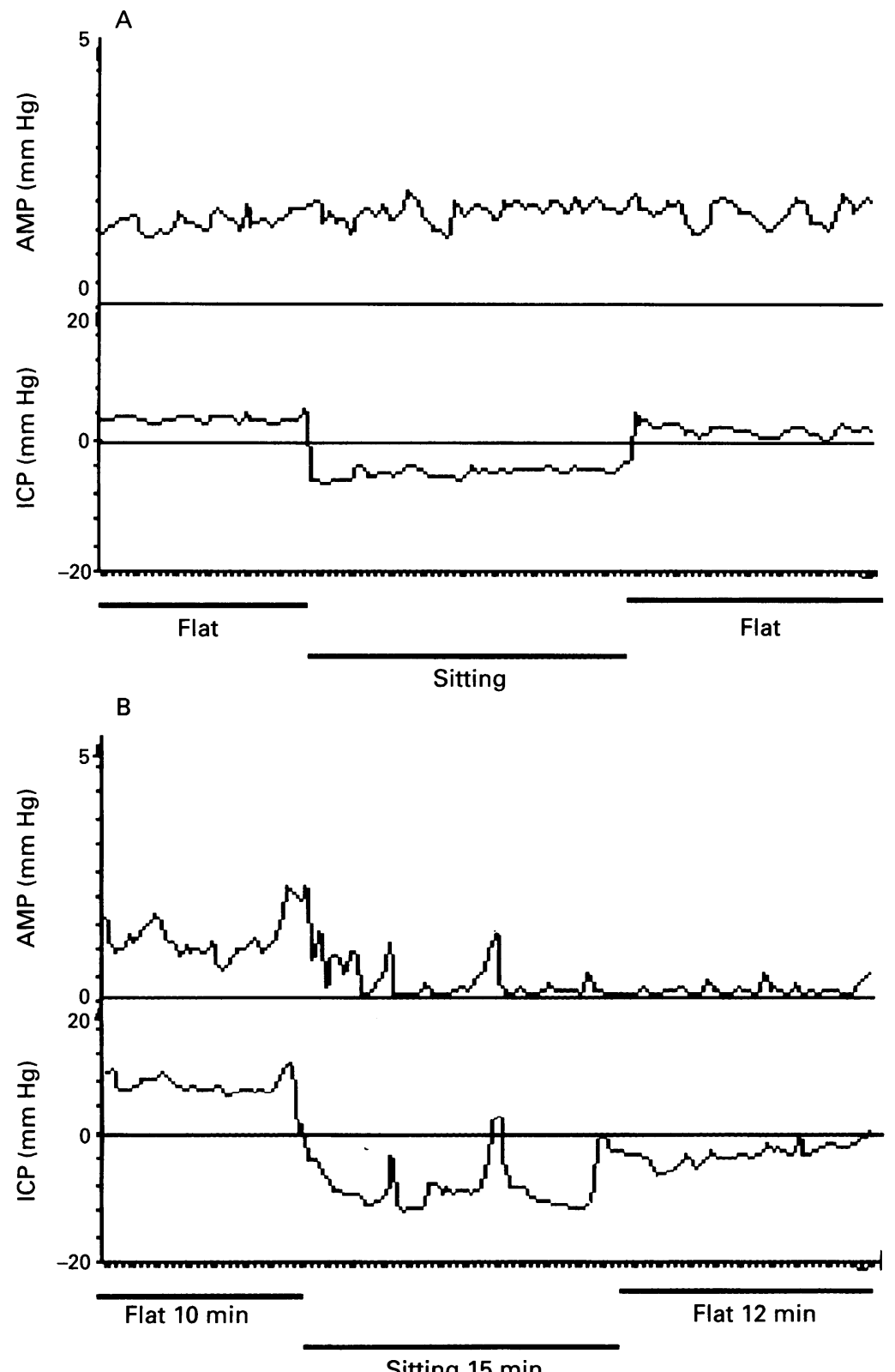

Figure 7 Tests for posture related overdrainage. (A) no overdrainage (patient with an antisyphon device put in-line with the shunt); pressure decreased in sitting position to -5 $\mathrm{mm} \mathrm{Hg}, \mathrm{AMP}$ did not react to change in the body position, after 15 minutes sitting ICP returned to the baseline value. (B) Overdrainage manifested by a decrease in ICP in sitting position below $-10 \mathrm{~mm} \mathrm{Hg}$, with simultaneous decrease in AMP. After the return to the horizontal position, ICP and AMP were significantly lower than at baseline.

the patient's ear, usually produces a further decrease in the pressure. If the pressure decreases to a value lower than $-10 \mathrm{~mm} \mathrm{Hg}$, with a gradual decrease in pulse amplitude, overdrainage is possible. If, after 10-15 minutes of sitting, the pressure and pulse amplitude in a horizontal position are lower than at the baseline, overdrainage is confirmed (fig 7).

OVERDRAINAGE RELATED TO NOCTURNAL VASOMOTOR WAVES (TWO PATIENTS)

Most contemporary valves usually have a low hydrodynamic resistance,,$^{51}{ }^{52}$ a property which may result in the overdrainage related to the periodic oscillations of the cerebrovascular volume. The expanding cerebrovascular bed acts like a membrane of a water pump with a distal low resistance valve. Overdrainage seen after a period of moderately raised oscillating
ICP during REM sleep is usually manifested by a period of low (negative) pressure and a low amplitude of the ICP pulse wave (fig 8). Early morning headaches should not be assumed to be due to "high pressure". They may be a consequence of low pressure caused by nocturnal overdrainage.

\section{Discussion}

Does lumbar infusion supported by computer data analysis give as precise measurement of the CSF outflow resistance as other methods? Borgesen et $a l^{53}$ compared the computerised infusion test with their lumboventricular perfusion, ${ }^{54}$ a method giving an accurate estimate of the resistance at multiple intraventricular pressure levels. Both tests were compared in a heterogeneous group of patients presenting with ventricular dilatation. Strong correlation $(r=0.98 ; \mathrm{P}<0.001)$ between the results of the tests was found. They concluded that computerised lumbar infusion is as accurate in the measurement of the conductance of CSF outflow as the lumboventricular perfusion but is much less invasive.

The purpose of the test in clinical practice is to measure the cerebrospinal compensatory variables and use them to predict the results of shunting. The test is helpful in such a prediction, ${ }^{1421}$ but no single variable is predictive on its own. ${ }^{18}$ Recent studies showed that in certain groups of patients, such as those with adult hydrocephalus syndrome, there is no good predictor of outcome. ${ }^{3355}$ Also, idiopathic normal pressure hydrocephalus is a difficult area for outcome prediction, ${ }^{19}$ but with some encouraging reports. ${ }^{42}$

Often, an improvement after shunting is difficult to assess and may be very short lasting and misleading in making comparison between patients. Three components contribute to postshunt improvement: accurate diagnosis, surgery, and shunt performance in vivo.

For diagnosis, a hierarchy of examinations and tests should form an integrated picture, in which the pressure-volume study is only one of multiple components. Clinical examination, brain imaging (CT and MRI to assess white matter lesions ${ }^{1855}$ in complicated cases), and neuropsychological tests are essential to make a proper decision about shunting. Pressurevolume testing should be preceded by overnight ICP monitoring if suitable access (Ommaya or Rickham reservoir) is available. However, even after positive diagnosis, a shunt may not resolve the clinical symptoms, because of postsurgical complications, shunt obstruction, or a mismatch between the patient's own CSF circulatory reserve and the shunt's pressure-flow performance. It has been assessed that $30 \%$ of shunts develop failure during the first year with a subsequent rate of malfunction of $5 \%$ per year, ${ }^{52}$ giving a total rate of shunt revisions of $80 \%$ within 12 years. As shunt related complications are likely and a pressure-volume study is a reliable test of shunt function in vivo, a baseline measurement performed before shunting is very help- 

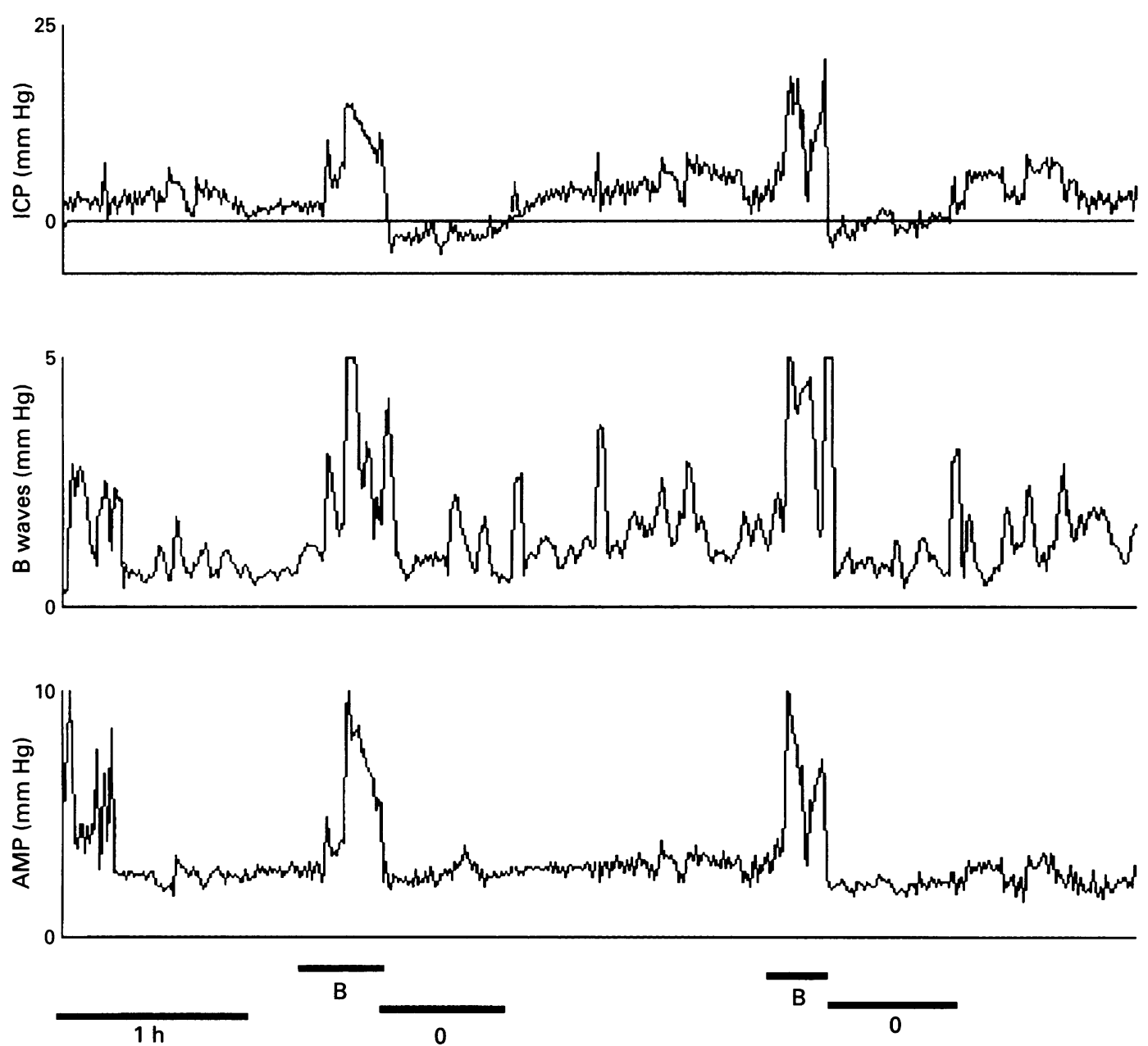

Figure 8 An overdrainage related to the nocturnal vasomotor waves; patient with the valve equipped with a siphon control device (Delta, performance level 2). Two episodes of a strong, around 30 minutes long, $B$ wave activity were recorded (the raised ICP, pulse amplitude $A M P$, and the computer detected power of $B$ waves). After each episode the baseline pressure fell to negative values $(0)$ for at least one hour.

ful. Also, some indications for choosing a particular type of the shunt may be made using pressure-volume tests.

Overdrainage related to posture ${ }^{5657}$ may lead to serious complications, ${ }^{58-60}$ particularly in patients with the combination of gross ventricular dilatation and a high pressure-volume index $(>26 \mathrm{ml})$. Therefore, siphon controlling devices should be considered in such patients. Shunts having a high hydrodynamic resistance (flow regulating, mitre valves, lumboperitoneal shunts) should be avoided in patients with a low cerebrospinal compliance and large amplitude of ICP B waves recorded during the test or overnight. The opening pressure of programmable valves should be matched to the recorded resting CSF pressure with a careful stepwise reduction in time to avoid subdural collections, and lead to normalisation of ventricles and resolution of clinical symptoms. Underdrainage is likely in rare patients with increased formation rate of CSF or with very high resistance to CSF outflow ( $>20 \mathrm{~mm} \mathrm{Hg} / \mathrm{ml} / \mathrm{min}$ ) in whom a flow regulating device, which is able to drain CSF with a maximal rate $0.3 \mathrm{ml} / \mathrm{min}$, is implanted.

\section{Appendix}

MATHEMATICAL MODELLING OF CSF CIRCULATION In normal conditions, without long term fluctuations of the cerebral blood volume, production of CSF and external infusion into CSF spaces is balanced by its storage and reabsorption:

$$
\begin{aligned}
& \text { Production of CSF + external infusion }= \\
& \text { storing of CSF + reabsorption of CSF }
\end{aligned}
$$

Production of CSF is almost constant. ${ }^{61-63}$ Reabsorption is proportional to the gradient between CSF pressure $(p)$ and pressure in sagittal sinuses $\left(p_{s s}\right)$.

$$
\text { Reabsorption }=\frac{p-p_{s s}}{R}
$$

Coefficient $R$ is named the resistance to CSF reabsorption or outflow (units: $\mathrm{mm} \mathrm{Hg} / \mathrm{ml} / \mathrm{min}$ ). Normal value of this resistance is $6-10 \mathrm{~mm} \mathrm{Hg} / \mathrm{ml} / \mathrm{min} .{ }^{612}$ A resistance above $12-13 \mathrm{~mm} \mathrm{Hg} / \mathrm{ml} / \mathrm{min}$ can be interpreted as raised. ${ }^{71011416}$ Storing of CSF is proportional to the cerebrospinal compliance $C$ (units: $\mathrm{mm} \mathrm{Hg} / \mathrm{ml} / \mathrm{min}$ ).

$$
\text { Storing }=C \cdot \frac{d p}{d t}
$$

The compliance of the cerebrospinal space is inversely proportional to the gradient of CSF pressure $p_{0}(4) .^{3435}$

$$
C=\frac{1}{E \cdot\left(p-p_{0}\right)}
$$

Some authors suggest that relation (4) is valid only above the certain pressure level named the "opitmal pressure" 363764 ; however, this is still a point of some dispute. Coefficient $E$ is the cerebral elasticity (units: $\left.\mathrm{ml}^{-1}\right)$. Elevated elasticity $\left(>0.18 \mathrm{ml}^{-1}\right)$ signifies a poor pressure-volume compensatory reserve. ${ }^{111221}$ The reference pressure $p_{o}$ is a parameter of uncertain 


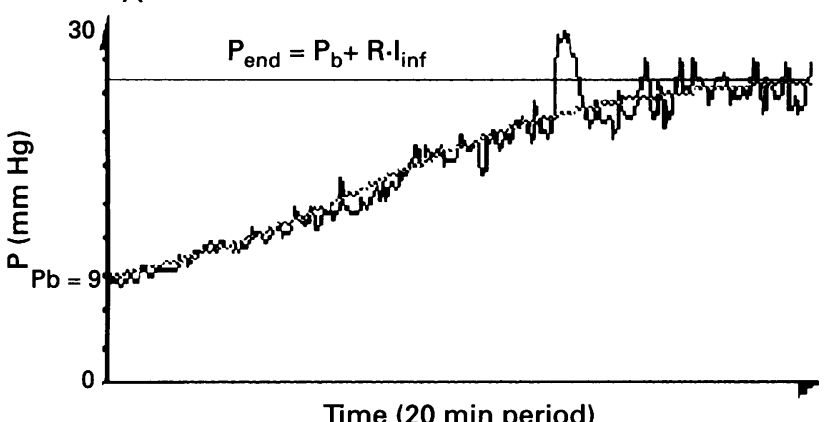

Time (20 $\mathrm{min}$ period)

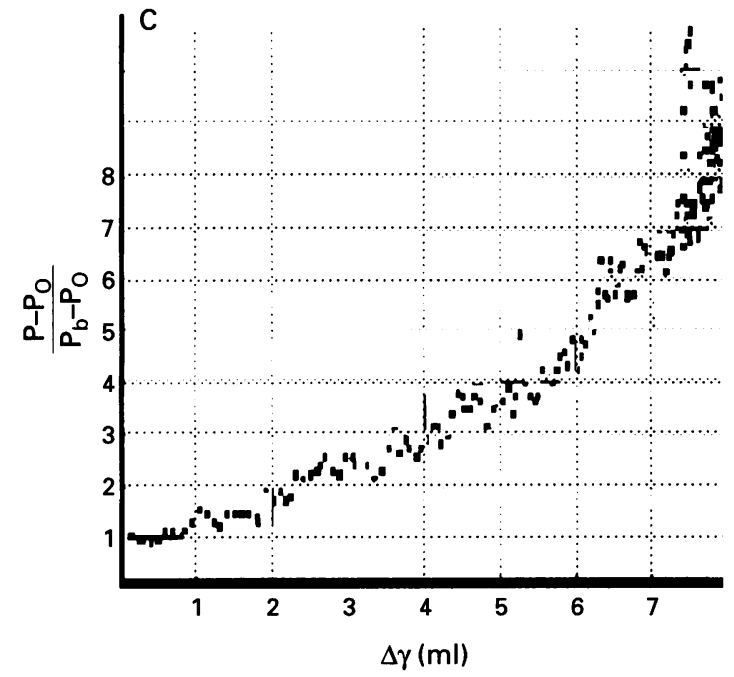

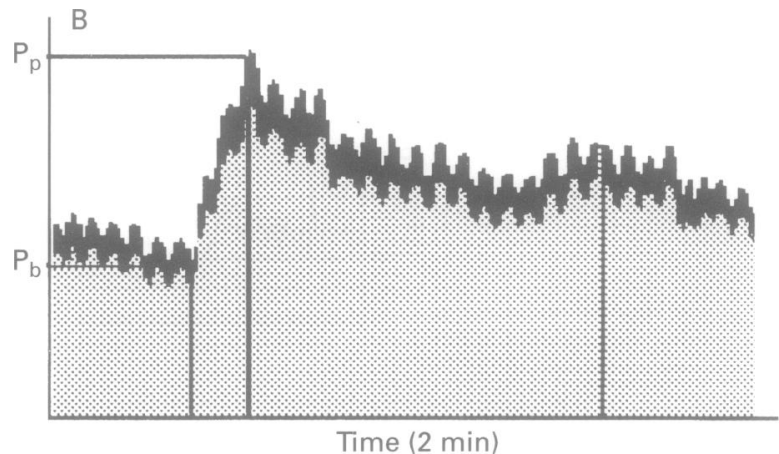

D

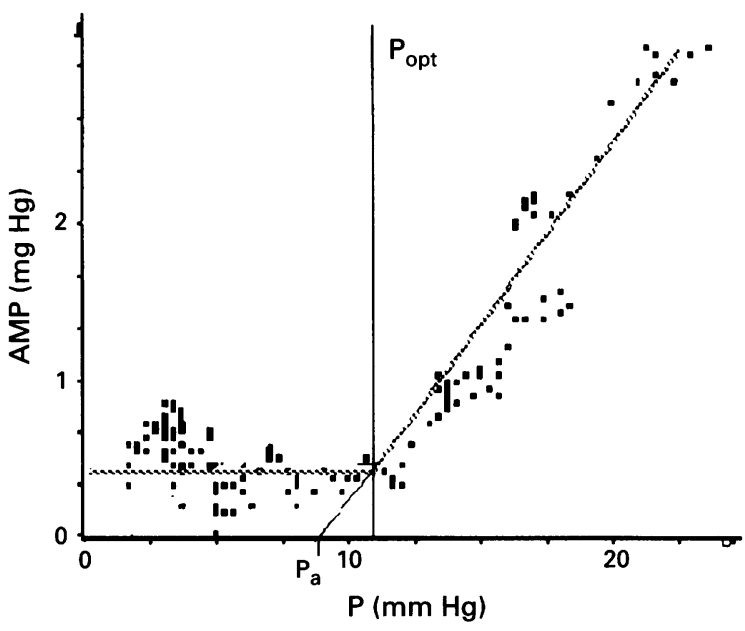

Figure 9 Different techniques used for the analysis of the pressure-volume tests. (A) Example of CSF pressure recorded during an infusion test and a modelling curve described by (6). The least mean square fit of the analytical curve to the real pressure enables an accurate measurement of the compensatory parameters. (B) Example of the pressure response to the bolus injection of saline. Pressure is increasing from $P_{b}$ to $P_{p}$ after a very rapid addition of volume $(V)$. (C) Real volume-pressure relation detected during an infusion test. Volume load $(V)$ is calculated as the balance of the volume infused, produced, and reabsorbed during infusion. Pressure rise ( $y$ axis) is expressed as the ratio of actual pressure and baseline pressure. (D) Relation between pulse amplitude $(A M P)$ and mean pressure $(P)$ recorded during the infusion test. This is one case in which the lower breakpoint, marked as $P_{\text {opt }}$ was detected. In such a case all equations (4-8) are valid only for $P>P_{\text {opp }}$ which is taken into account in the computer calculations (such a breakpoint can be detected in $1-3 \%$ of infusion tests).

significance. Some authors suggest that it is a pressure in the venous compartment and may be equal to $p_{s s}{ }^{37}$ Others assume that this variable can be neglected. ${ }^{34} 35$

The relation (4) reflects the most important law of the cerebrospinal dynamic compensation: the compliance of the brain decreases when the CSF pressure increases.

Combination of (1) with (2) and (4) gives a final equation (5):

$$
\frac{1}{E \cdot\left(p-p_{0}\right)} \cdot \frac{d p}{d t}+\frac{p-p_{b}}{R}=I(t)
$$

where $I(t)$ is the rate of external volume addition and $p_{b}$ is a baseline pressure.

Equation (5) can be solved for various types of external volume additions $I(t)$. The most common in clinical practice is:

(a) a constant infusion of CSF $(I(t)=0$ for $t<0$ and $I(t)=I_{\text {inf }}$ for $t>0$ ): see fig 9A:

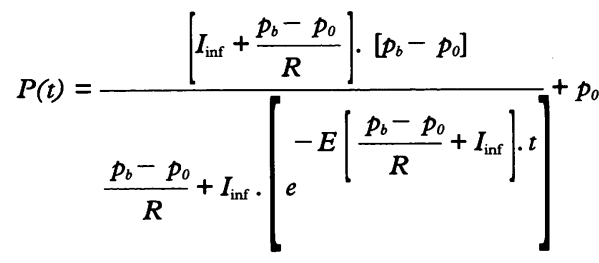

The analytical curve (6) can be matched to the actual recording of the pressure during the test, which results in accurate estimation of unknown parameters: $R, E$, and $p_{0}$. (b) A bolus injection of CSF (volume $\Delta V$ ): see fig 8:

$$
P(t)=\frac{\left(p_{b}-p_{0}\right) \cdot e^{E\left[\Delta V+\frac{p_{b}-p_{0}}{R} \cdot t\right]}}{1+e^{E \Delta V} \cdot\left[e^{E \cdot \frac{p_{b}-p_{0}}{R} \cdot t}-1\right]}+p_{0}
$$

The bolus injection can be used for calculation of the so-called pressure-volume index (PVI), having an intepretation of the volume added externally to produce the tenfold increase in the pressure ${ }^{34} 35$ :

$$
P V I \stackrel{\text { def }}{=} \frac{\Delta \mathrm{V}}{\log _{10}\left(\frac{p_{p}-p_{0}}{p_{b}-p_{0}}\right)} ; \quad P V I \cong \frac{1}{0.434 . E}
$$

$P V I$ is theoretically an inverse of the brain elasticity $E$. The pressure-volume compensatory reserve is insufficient when $P V I<13 \mathrm{ml}$. The value of $P V I$ above $26 \mathrm{ml}$ signifies an "overcompliant" brain.

The formula (7) for time $t=0$ describes the shape of the relationship between the effective volume increase $\Delta V$ and the CSF pressure, called the pressure-volume curve (see fig 9C):

$$
p=\left(p_{b}-p_{0}\right) \cdot e^{E \Delta V}+p
$$

Finally, the equation (7) can be helpful in theoretical evaluation of the relationship between the pulse wave amplitude of CSF pressure and the mean CSF pressure. If we presume that the rise of the blood volume after a heart contraction is equivalent to a rapid bolus 
addition of CSF fluid at the baseline pressure $p_{b}$, the pulse amplitude $(A M P)$ can be expressed as:

$$
A M P=p_{p}-p_{b}=\left(p_{b}-p_{0}\right) \cdot\left(e^{E \Delta V}-1\right)
$$

In almost all cases, when the CSF pressure is being increased by external volume addition the pulse amplitude is rising. The gradient of the regression line between $A M P$ and $p$ is proportional to the elasticity. The intercept, theoretically, marks the reference pressure $p_{0}$. The mathematical modelling of CSF dynamics has several applications. In all pressure-volume testing techniques model (5) is identified using various algorithms and various volume-adding techniques: pressure-controlled servoinfusion, ${ }^{6566}$ constant rate infusion, ${ }^{933}$ bolus injection, ${ }^{203536}$ multiple rate perfusion, ${ }^{54}$ computer controlled drainage,${ }^{67}$ etc.

The presented model has, however, limited scope: it cannot interpret dynamic interactions between the rising CSF pressure, expanding ventricles, and cerebral blood volume. More complex, ${ }^{68}$ or even multicompartmental (Blood-CSF), dynamic models are helpful in simulation of such phenomena. ${ }^{69-71}$

Many thanks to Mr Peter Spittaler for valuable comments and critical revision and to the following colleagues from hospitals in Poland, Denmark, and the United Kingdom who contributed to refining of the computerised infusion test and its clinical verification: Dr L Batorski, Dr SE Borgesen, Professor F Gjerris, Dr E Guazzo, Dr A Hong, Dr W Maksymowicz, Dr P Kirkpatrick, Dr W Koszewski, Dr P Laniewski, Dr N Tisavipat, Dr J Tomaszewski, Dr A Walencik.

MC and PS are on leave from Warsaw University of Technology, Poland.

1 Schmidt JF, Andersen AR, Paulson OB, Gjerris F. Angiotensin converting enzyme inhibition, $\mathrm{CBF}$ autoregulation, and ICP in patients with normal pressure hydrocephalus. Acta Neurochir (Wien) 1990;106:9-12.

2 Vorstrup S, Christensen J, Gjerris, et al. Cerebral blood orstrup S, Christensen J, Gjerris, et al. Cerebral blood flow in patients with normal-pressure hydrocephalus
before and after shunting. 7 Neurosurg 1987;66:379-87.

3 Jagust WJ, Friedland RP, Budinger TF. Positron emission tomography with ${ }^{[18 \mathrm{~F}]}$ fluorodeoxyglucose differentiates normal pressure hydrocephalus from Alzheimer type
dementia. $\mathcal{F}$ Neurol Neurosurg Psychiatry 1985;48:109-16. dementia. F Neurol Neurosurg Psychiatry 1985;48:109-16.
McIntyre AW, Emsley RA. Shoplifting associated with normal pressure hydrocephalus: report of a case. $\mathcal{f}$ Geriatr Psychiatry Neurol 1990;3:229-30.

5 Graff J, Radford NR, Rezai K, et al. Regional cerebral blood flow in normal pressure hydrocephalus. $\mathcal{f}$ Neurol Neurosurg Psychiatry 1987;50:158-996.

6 Albeck MJ, Borgesen SE, Gjerris F, Schmidt JF, Sorensen PS. Intracranial pressure and cerebrospinal fluid outflow conductance in healthy subjects. F Neurosurg 1991;74: 597-600.

7 Borgesen SE, Gjerris F. The predictive value of conductance to outflow of CSF in normal pressure hydrotance to outflow of CSF in
cephalus. Brain 1982;105:65-86.

8 Morgan M, Johnston IH, Spittaler PJ. A ventricular infusion technique for the evaluation of treated and untreated hydrocephalus. Neurosurgery 1991;26:832-7.

9 Lundar T, Nornes H. Determination of ventricular fluid outflow resistance in patients with ventriculomegaly. $\mathcal{F}$ Neurol Neurosurg Psychiatry 1990;53:896-8.

10 Costabile G, Probst C. Intrathecal infusion test and decrease in shunt revisions and infections. Neurochirurgia (Stuttg) 1988;31:134-5.

11 Czosnyka M, Batorski L, Roszkowski M, et al. Cerebrospinal compensation in hydrocephalic children. Childs Nerv Syst 1993;9:17-22.

12 Ekstedt J. CSF hydrodynamic studies in man. Method of constant pressure CSF infusion. $\mathcal{F}$ Neurol Neurosurg

13 Malm J, Kristensen B, Karlsson T, Fagerlund M, Elfverson J, Ekstedt J. The predictive value of CSF dynamic tests in patients with the idiopathic hydrocephalus syndrome. Arch Neurol 1995;52:783-9.

14 Maksymowicz W, Czosnyka M, Zabolotny W, Koszewski $\mathrm{W}$. The communicating hydrocephalus versus brain atrophy-is a reliable differentiation possible? In: Nagai $\mathrm{H}$, Springer-Verlag, 1994:568-9.

15 Shapiro K, Fried A. The theoretical requirements of shunt design as determined by biomechanical testing in pediatric hydrocephalus. Childs Nerv Syst 1988;4:348-53.

16 Price DJ. Attempts to predict the probablity of clinical improvement following shunting of patients with presumed normal pressure hydrocephalus. In: Hoff JT, Betz $\mathrm{AL}$, eds. Intracranial pressure VII. Berlin: Springer-Verlag, 1989:390-93.

17 Gjerris F, Borgesen SE, Sorensen PS, et al. Resistance to cerebrospinal fluid outflow and intracranial pressure in patients with hydrocephalus after subarachnoid haemorpatients with hydrocephalus after subarachno

18 Pickard JD, Newton H, Greene A, et al. A prospective study of idiopathic normal pressure hydrocephalus- guidlines for outpatient investigation. In: Proceedings of the Society of British Neurological Surgeons with the New England Neurosurgical Society. $\mathcal{F}$ Neurol Neurosurg Psychiatry 1992;55:513-21.

19 Delwell EJ, de Jong DA, Avezaat CJJ. The relative prognostic value of CSF outflow resistance measurement in shunting for normal pressure hydrocephalus. In: Avezaat CJJ, van Eijndhoven JHM, Maas AIR, Tans JTJ, eds. Intracranial pressure VIII. Berlin: Springer-Verlag, 1993: 816-20.

20 Kosteljanetz M, Nehen AM, Kaalund J. Cerebrospinal fluid outflow resistance measurements in the selection of patients for shunt surgery in the normal pressure hydrocephalus syndrome. A controlled trial. Acta Neurochir (Wien) 1990;104:48-53.

21 Maksymowicz W, Czosnyka M, Koszewski W, et al. The role of cerebrospinal system compensatory parameters in estimation of functioning of implanted shunt system in patients with communicating hydrocephalus. Acta Neurochir (Wien) 1989:101:112-16.

22 Bradley WG Jr, Whittemore AR, Kortman KE, et al. Marked cerebrospinal fluid void: indicator of successful shunt in patients with suspected normal pressure hydrocephalus. Radiology 1991;178:459-66.

23 Foltz EL, Blanks JP, Yonemura K. CSF pulsatility in hydrocephalus: respiratory effect on pulse wave slope as an indicator of intracranial compliance. Neurol Res 1990; 12:67-74.

24 Chopp M, Portnoy HD. System analysis of intracranial pressure. Comparison of volume-pressure test and CSFpulse amplitude analysis. 7 Neurosurg 1980;53:516-27.

25 Drake JM, Saint-Rose CH, eds. Shunt complications. In: The shunt book. Oxford: Blackwell Science, 1995:23-92.

26 Czosnyka M, Maksymowicz W, Batorski L, Koszewski W. Comparison between classic differential and automatic shunt functioning on the basis of infusion tests. Acta Neurochir (Wein) 1990;106:1-8.

27 Maksymowicz W, Czosnyka M, Koszewski W, Szymanska $\mathrm{O}$, Zabolotny W. Post shunting improvement in hydrocephalic patients described by cerebrospinal compensatory parameters. In: Avezaat CJJ, van Eijndhoven JHM, Maas AIR, Tans JTJ, eds. Intracranial pressure VIII. Berlin: Springer-Verlag, 1994:829-32.

28 Sprung C, Collman H, Fuchs EC, et al. Pre- and postoperative evaluation of hydrocephalus using the infusion test. Adv Neurosurg 1977;4:463-70.

29 Reilly PL, Savage JP, Doecke L. Isotope transport studies and shunt pressure measurements as a guide to shunt and shunt pressure measurements as a
function. $B r ₹$ Neurosurg 1989;3:681-90.

30 Seppanen U, Serlo W, Saukkonen AL. Valvography in the assessment of hydrocephalus shunt function in children. Neuroradiology 1987;29:53-7.

31 Hara M, Kadowaki C, Konishi Y. A new method for measuring cerebrospinal fluid flow in shunts. $f$ Neurosurg 1983;58:557-61.

32 Czosnyka M,Batorski L,Laniewski P, et al. A computer system for the identification of the cerebrospinal compensatory model. Acta Neurochir (Wein) 1990;105:112-16.

33 Katzman R, Hussey F. A simple constant infusion manometric test for measurement of CSF absorption. Neurology (Minneap) 1970;20:534-44.

34 Marmarou A. A theoretical model and experimental evaluation of the cerebrospinal fluid system [thesis]. Philadelphia, PA: Drexel University, 1973.

35 Marmarou A, Shulman K, Rosende RM. A non-linear analysis of CSF system and intracranial pressure dynamics. F Neurosurg 1978;48:332-44.

36 Szewczykowski J, Sliwka S, Kunicki A, et al. A fast method of estimating the elastance of intracranial system. $\mathcal{F}$ Neurosurg 1977;47:19-25.

37 Avezaat CJJ, Eijndhoven JHM. Cerebrospinal fluid pulse pressure and craniospinal dynamics. A theoretical, clinical and experimental study [thesis]. The Hague: Jongbloed A, 1984.

38 Frieden H, Eksted J. Estimation of CSF outflow resistance: model validation and resistance calculation by the method of CSF volume accounting. In: Gjerris F, Borgesen SE, Sorensen PS, eds. Outflow of cerebrospinal fluid. Copenhagen: Munksgaard, 1989:198-210.

39 Sliwka S: Static and dynamic cerebrospinal elastance-clinical verification. In: Miller JD, Teasdale G, Rowan JO, Galbraith SL, Mendelow AD, eds. Intracranial pressure VI. Berlin: Springer-Verlag, 1986:84-8.

40 Bolander HG. A new method for longterm lumbar pressure monitoring with a fiber optic catheter. Acta Neurochir (Wien) 1990;105:135-9.

41 Cardoso ER, Piatek D, Del Bigio MR, Stambrook M, Sutherland JB. Quantification of abnormal intracranial pressure waves and isotope cisternography for diagnosis of occult communicating hydrocephalus. Surg Neurol 1989;31:20-7.

42 Gjerris F, Borgesen SE. Pathophysiology of CSF circulation. In: Neurosurgery. The scientific basis of clinical practice. Crockard A, Hayward A, Hoff JT, eds. Oxford: Blackwell Scientific, 1992:146-74

43 Pickard JD, Teasdale G, Matheson $\mathrm{M}$, et al. Intraventricular pressure waves-the best predictive test for shunting in normal pressure hydrocephalus. In: Shulman K, Marmarou A, Miller JD, Becker DP, Hochwold GM, Brock M, eds. Intracranial pressure IV. Berlin: SpringerBrock M, eds. Intracranid

44 Klingelhofer J, Sander D. Dynamics in cerebral blood flow velocities in sleep. Fournal of Cardiovascular Technology
1995;97:142-8. 
45 Newell DW, Aaslid R, Stoss R, Reulen HJ. The relationship of blood flow velocity fluctuations to intracranial pressure B waves. $\mathcal{F}$ Neurosurg 1992:76:415-21.

46 Pickard JD, Czosnyka M. Management of raised intracranial presure. F Neurol Neurosurg Psychiatry 1993;56: 845-58.

47 Lemaire JJ, Chazal J, Gutknecht JL, Picard P, Irthum B, Boire JY. Effects of acute compliance fluctuation on slow ICP waves: frequential aspects. In: Nagai $H$, Kamiya K, Ishii S, eds. Intracranial pressure IX. Berlin: SpringerVerlag, 1994:498-501

48 Whitehouse H, Czosnyka $M$, Smielewski P, Pickard JD. Blood flow velocity in the middle cerebral artery during lumbar CSF infusion tests in patients with ventricular lumbar CSF infusion tests in patients with ventricular dilatation. In: Nagai $\mathrm{H}$, Kamiya K, Ishii S, eds. Intra-

49 Hara K, Nakatani S. Detection of the B waves in the oscilation of intracranial pressure by fast Fourier transform. Med Inf (Lond) 1990;15:125-31

50 Saint-Rose C, Hooven MD, Hirsch JF. A new approach in the treatment of hydrocephalus. $\mathcal{F}$ Neurosurg $1987 ; 66$ : 213-26.

51 Aschoff A, Kremer P, Benesch C, et al. Overdrainage and shunt technology. Childs Nerv Syst 1995;11:193-202.

52 Drake JM, Saint-Rose CH, eds. Shunt complications. In: The shunt book. Oxford: Blackwell Science, 1995.

53 Borgesen SE, Albeck MJ, Gjerris F, Czosnyka M. Computerized infusion test compared to conventional lumbar-ventricular perfusion for measurement of resistance to CSF outflow. Acta Neurochir (Wein) 1992;119: tance to 16.

54 Borgesen SE, Gjerris F, Sorensen SC. The resistance to cerebrospinal fluid absorption in humans. A method of evaluation by lumbo-ventricular perfusion, with particular reference to normal pressure hydrocephalus. Acta Neurol Scand 1978;57:88-96.

55 Graff J, Radford NR, Godersky JC, Jones MP. Variables predicting surgical outcome in symptomatic hydrocephalus in the elderly. Neurology 1989;39:160-14.

56 Chapman PH, Cosman ER, Arnold MA. The relationship between ventricular fluid pressure and body position in normal subjects and subjects with shunts: a telemetric study. Neurosurgery 1990;26:1819.

57 Pudenz RH, Foltz EL. Hydrocephalus: overdrainage by ventricular shunts. A review and recommendations. Surg ventricular shunts. A revie
58 Serlo W, Saukkonen AL, Heikkinen E, von Wendt L. The incidence and management of the slit ventricle syndrome. Acta Neurochir (Wien) 1989;99:113-6.

59 Epstein F, Lapras C, Wisoff JH. "Slit ventricle syndrome". etiology and treatment. Pediatr Neurosci 1988;14:5-10.

60 Foltz EL, Blanks JP. Symptomatic low intracranial pressure in shunted hydrocephalus. 7 Neurosurg 1988;68:401-8.

61 Davson H, Welch K, Segal MB. Physiology and pathophysiology of cerebrospinal fluid. Edinburgh: Churchill Livingstone 1987:189-246.

62 Davson H. Formation and drainage of the CSF in hydrocephalus. In: Shapiro K, Marmarou A, Portnoy $\mathrm{H}$, eds. cephalus. In: Shapiro K, Marmarou A, Portnoy H, eds.

$63 \mathrm{McComb}$ JG. Recent research into the nature of cerebrospinal fluid formation and absorption. $\mathcal{F}$ Neurosurg 1983;59:369-83.

64 Szewczykowski J, Dytko P, Kunicki A, et al. Method of estimating intracranial decompensation in man. $\mathcal{F}$ Neurosurg 1976;45:155-63.

65 Sklar FH, Beyer CW, Ramanathan M, et al. Servo-controlled lumbar infusions: a clinical tool for determination of CSF dynamics as a function of pressure. Neurosurgery 1978;3:170-8.

66 Frieden $\mathrm{H}$, Ekstedt J. Instrumentation for cerebrospinal fluid hydrodynamic studies in man. Med Biol Eng Comput 1982;20:167-180.

67 Mielewski P, Czosnyka M, Roszkowski M, Walencik A Identification of the cerebrospinal compensatory mechanisms via computer controlled drainage of CSF. Childs Nerv Syst 1995;11:297-300.

68 Rekate HL, Brodkey JA, Chizeck HJ, el Sakka W, Ko WH Ventricular volume regulation: a mathematical model and computer simulation. Pediatr Neurosci 1988;14 $77-84$.

69 Hoffmann O. CSF dynamimics: integration of pulsator components and autoregulation into mathematical model. In: Ishii S, Nagai H, Brock $M$, eds. Intracranial pressure V. Berlin: Springer-Verlag, 1983:169-73.

70 Ursino M, Di Giammarco P. A mathematical model of the relationship between cerebral blood volume and intracranial pressure changes: the generation of plateau waves. Ann Biomed Eng 1991;19:15-25.

71 Czosnyka M, Pickard J, Whitehouse H, Piechnik S. The hypearemic response to a transient reduction in cerebral perfusion pressure-a modelling study. Acta Neurochir (Wien) 1992;115:90-7.

\section{NEUROLOGICAL STAMP}

\section{St Apollonia (died about AD 249)}

During an Alexandrian riot against the Christians, Apollonia, an elderly deaconess, was repeatedly struck in the face. Her teeth were torn out and her jaws were broken but she refused to renounce her Christian faith. A bonfire was built. Apollonia, threatened with being burnt alive, was asked once more to return to the Roman gods. Instead, she uttered a short prayer and walked into the flames. Apollonia was canonised about 50 years after her death. She became the patron saint of toothache and the patroness of the dental profession.

A stamp issued in 1979 by San Marino for the 13th stomatological conference (Stanley Gibbons 1114, Scott 959) reproduces a 14th century wood carving which is part of the Wessler Collection at the Royal School of Dentistry in Stockholm. St Apollonia is shown with one hand laid on the swollen cheek of a toothache sufferer. Her insignia, a tooth held by forceps, is shown in her other hand.

L F HAAS

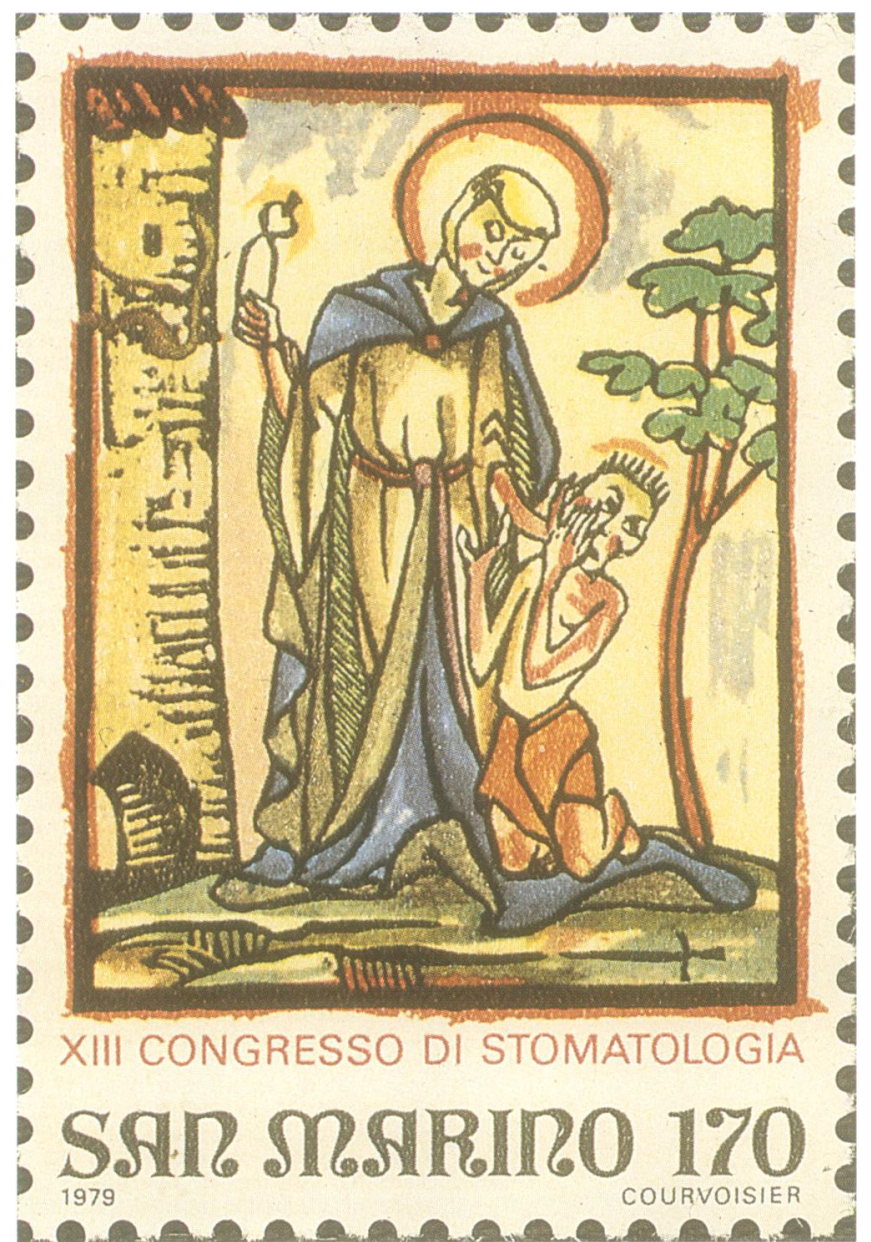

